\title{
Localized Synaptic Actions of Neurotrophin-4
}

\author{
Xin-hao Wang, Benedikt Berninger, and Mu-ming Poo \\ Department of Biology, University of California at San Diego, La Jolla, California 92093-0357
}

Neurotrophins secreted by the postsynaptic target cell may participate in activity-dependent synaptic modification during development and in the mature brain. A fundamental question of how neurotrophins can sculpt synaptic connections is whether neurotrophin-induced synaptic changes are spatially restricted to the site of neurotrophin secretion or whether they can spread to neighboring synapses. Using a model system of nerve-muscle coculture in which neurotrophin-4 (NT-4) is overexpressed in a subpopulation of postsynaptic myocytes, we demonstrated that presynaptic potentiation is restricted to syn- apses on myocytes overexpressing NT-4 without affecting nearby synapses formed by the same neuron on control myocytes. Likewise, postsynaptic modulation of acetylcholine channels by secreted NT-4 is spatially restricted to $<60 \mu \mathrm{m}$ from the site of NT-4 secretion. Therefore, activity-dependent secretion of neurotrophins can result in highly localized modification of neuronal connections.

Key words: Xenopus; synaptic transmission; neuromuscular junction; embryo injection; acetylcholine receptor; TrkB receptor
Target-derived neurotrophic factors are essential for the survival and differentiation of developing neurons (Purves and Lichtman, 1985; Barde, 1989; Oppenheim, 1991). Recent evidence indicates that neurotrophins, a family of proteins related to nerve growth factor (NGF), may also participate in activity-dependent modification of synaptic connections (Lo, 1995; Thoenen, 1995; Berninger and Poo, 1996; Bonhoeffer, 1996; Cellerino and Maffei, 1996; Katz and Shatz, 1996; Lewin and Barde, 1996). The expression of NGF and brain-derived neurotrophic factor (BDNF) in central neurons can be regulated by electrical or synaptic activity (Gall and Isackson, 1989; Lu et al., 1991; Zafra et al., 1991). Furthermore, secretion of NGF, BDNF, and NT-4 can be enhanced by neuronal or synaptic activity (Blöchl and Thoenen, 1995; Goodman et al., 1996; Wang and Poo, 1997). On the other hand, neurotrophins have been shown to modulate the efficacy of synaptic transmission. Exogenous application of BDNF or neurotrophin-3 (NT-3) leads to a rapid potentiation of synaptic transmission in several cell culture preparations (Lohof et al., 1993; Kim et al., 1994; Lessmann et al., 1994; Levine et al., 1995) and brain slices (Kang and Schuman, 1995). In hippocampal slices from BDNF knock-out mice, long-term potentiation (LTP) in the CA1 region is severely impaired and can be restored by reintroduction of BDNF into the CA1 region (Korte et al., 1995, 1996; Patterson et al., 1996). Similarly, scavenging of BDNF by TrkB-IgG was shown to interfere with either the induction or maintenance of LTP in hippocampal slice, depending on the precise induction protocol (Figurov et al., 1996; Kang et al., 1997). These results have led to the hypothesis that neurotrophins released from postsynaptic cells can modify synaptic function, and such modification can be regulated by synaptic activity, thereby contributing to the activity-dependent refinement of synaptic connections.

\footnotetext{
Received Jan. 9, 1998; revised March 27, 1998; accepted April 13, 1998.

This work was supported by National Institutes of Health Grant NS22764. B.B. is supported by a fellowship from the Human Frontier Science Program Organization. We thank Genentech Inc. for providing Trk-IgG fusion proteins.

Correspondence should be addressed to Dr. Mu-ming Poo, Department of Biology, University of California at San Diego, La Jolla, CA 92093-0357.

Copyright (C) 1998 Society for Neuroscience $\quad 0270-6474 / 98 / 184985-08 \$ 05.00 / 0$
}

In a previous study (Wang and Poo, 1997), we found that neuromuscular synapses made on NT-4-overexpressing myocytes in nerve-muscle cultures exhibit a higher level of spontaneous transmitter release, as well as an enhanced postsynaptic response to the transmitter. Furthermore, repetitive stimulation of the presynaptic neuron resulted in a transient potentiation of evoked synaptic transmission and enhanced postsynaptic responses at synapses formed on NT-4-overexpressing myocytes. These results strongly supported the notion that neurotrophins secreted from the postsynaptic cell can indeed serve for retrograde as well as autocrine modulation of synaptic function in an activitydependent manner.

Several pieces of evidence have shown that changes in the efficacy of synaptic transmission induced by synaptic activity, including LTP or long-term depression (LTD), are not restricted to the activated synapse but can spread over considerable distance (Bonhoeffer et al., 1989; Schuman and Madison, 1994; Cash et al., 1996; Engert and Bonhoeffer, 1997; Fitzsimonds et al., 1997; Schuman, 1997). For instance, in Xenopus nerve-muscle cultures, LTD induced at one neuromuscular synapse can spread to distant synapses made by the same neuron onto other myocytes (Cash et al., 1996). This spread of LTD was apparently mediated by signaling in the presynaptic cytoplasm. In the present study, we have examined whether presynaptic modulation induced by postsynaptic release of NT-4 at Xenopus neuromuscular synapses can similarly spread to neighboring synapses or whether it is spatially restricted to the site of secretion. Likewise, we have determined the spatial range within which autocrine modulation of postsynaptic responses by secreted NT-4 can spread in a muscle cell.

\section{MATERIALS AND METHODS}

In vitro transcription and embryo injection. In vitro transcription and embryo injection were performed as described previously (Wang and Poo, 1997). Synthetic mRNAs for NT-4 and green fluorescent protein (GFP) were mixed 1:1, and 16 ng of mRNA was injected into one cell of two-cell stage embryos using a stimulator-gated pressure ejection system (Picospritzer; General Valve, Fairfield, NJ). The expression of NT-4 in nerve and muscle cells in 1-d-old cultures made from the injected embryos was confirmed by immunocytochemical staining using NT-4 
A
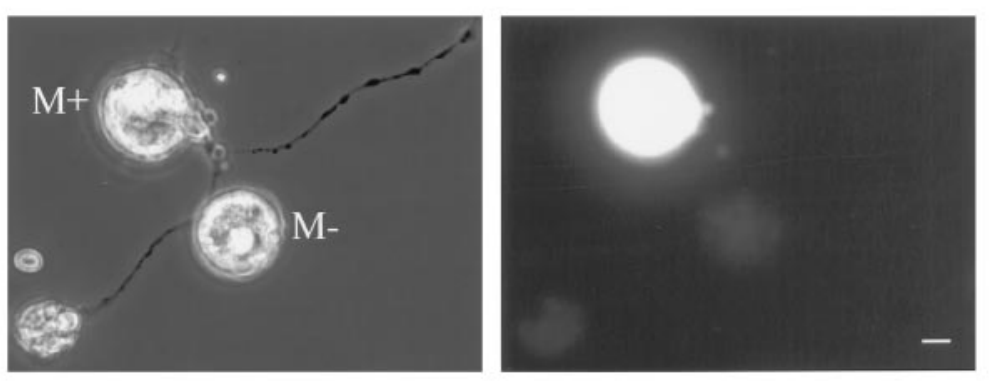

Figure 1. Localized presynaptic action of NT-4. $A$, Phase-contrast (left) and fluorescence (right) images of a spinal neuron innervating two myocytes, one derived from a blastomere injected with NT-4 and GFP mRNA $(M+)$ and the other $(M-)$ from a uninjected blastomere of the same Xenopus embryo. Scale bar, $10 \mu \mathrm{m}$. $B$, Continuous traces depict simultaneous whole-cell recordings from a myocyte overexpressing NT-4 $(M+)$ and a control myocyte $(M-)$ innervated by the same neuron. Downward deflections are MEPSCs or EPSCs, samples of which are shown below at a higher time resolution. EPSCs were elicited at a low frequency (at times indicated by tick marks). Calibration: slow traces, $1 \mathrm{nA}, 1 \mathrm{~min}$; fast traces, $1 \mathrm{nA}, 8 \mathrm{msec}$.

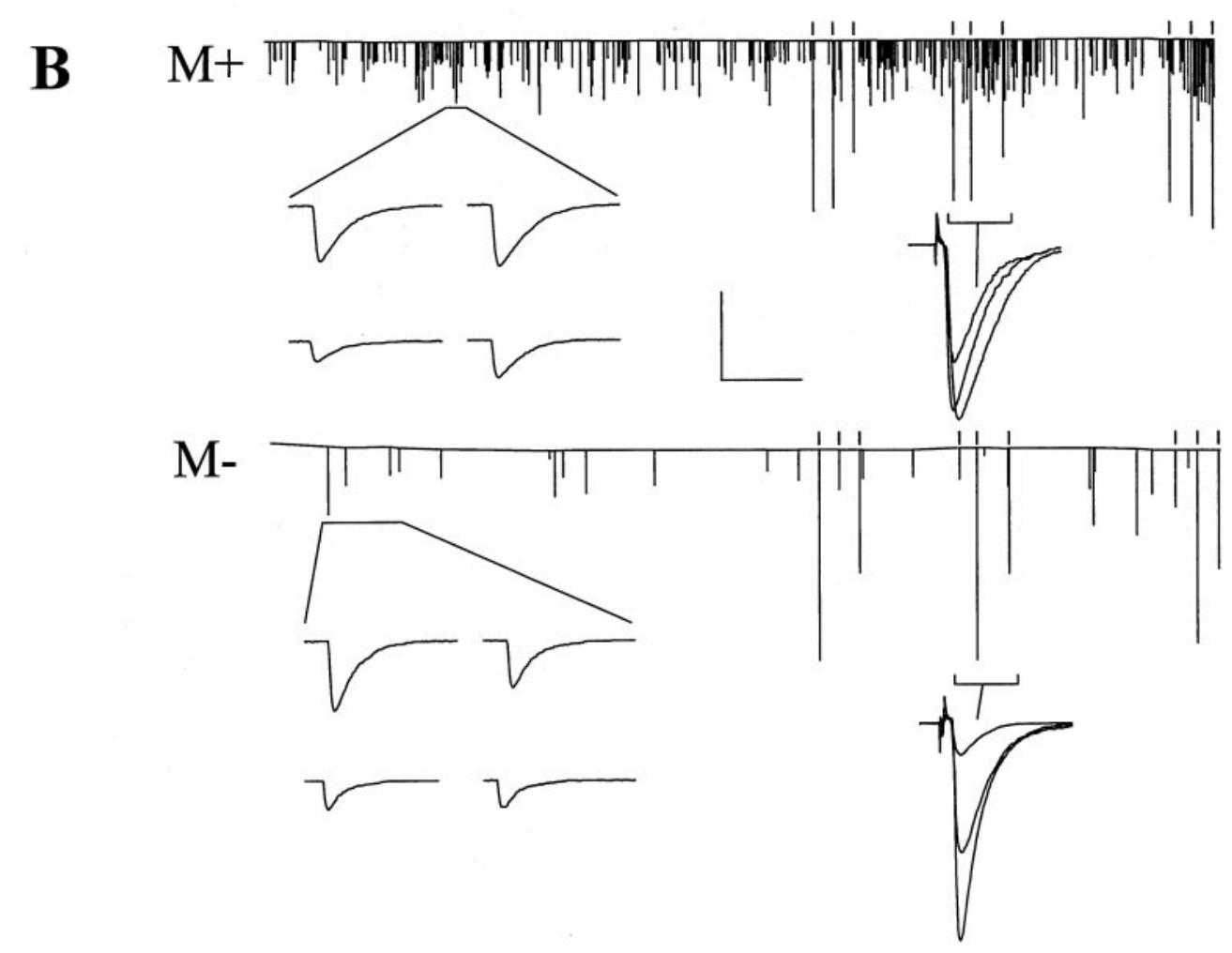

antibodies (Wang and Poo, 1997). That the expression of GFP provides a reliable indicator of NT-4 expression in living cells was also confirmed by the colocalization of NT-4 immunocytochemical staining and green fluorescence (Wang and Poo, 1997).

Culture preparation. Preparation of Xenopus nerve-muscle cultures followed the method described previously (Spitzer and Lamborghini, 1976; Tabti and Poo, 1991). The cells were plated on clean glass coverslips and were used for experiments after $24 \mathrm{hr}$ incubation at room temperature $\left(20-22^{\circ} \mathrm{C}\right)$. The culture medium consisted of $(\mathrm{v} / \mathrm{v}) 50 \%$ Leibovitz's medium (L-15; Life Technologies, Gaithersburg, MD), 1\% fetal bovine serum (Life Technologies), and 49\% Ringer's solution (in mM: $115 \mathrm{NaCl}, 2 \mathrm{CaCl}_{2}, 2.5 \mathrm{KCl}$, and 10 HEPES, $\mathrm{pH} 7.3$ ).

Electrophysiology. Synaptic currents were recorded from innervated muscle cells by the whole-cell recording method (Hamill et al., 1981; Evers et al., 1989) using a patch-clamp amplifier (Axopatch 1A, Axon Instruments). The solution inside the recording pipette contained (in $\mathrm{mM}$ ): $150 \mathrm{KCl}, 1 \mathrm{NaCl}, 1 \mathrm{MgCl}_{2}$, and 10 HEPES, $\mathrm{pH}$ 7.2. Recordings were made at room temperature in culture medium. Extracellular stimulation of the presynaptic neuron was made by a patch electrode at the cell body under loose-seal conditions. To study postsynaptic action of NT-4 on the kinetics of ACh-induced currents, perforated patch recording was made from the myocyte to prevent washout of the cell content during prolonged whole-cell recording. The pipette solution for perforated patch recording contained: $130 \mathrm{~mm}$ potassium gluconate, $20 \mathrm{~mm}$
$\mathrm{KCl}, 1 \mathrm{~mm} \mathrm{NaCl}, 1 \mathrm{~mm} \mathrm{MgCl}_{2}, 10 \mathrm{~mm}$ HEPES, $\mathrm{pH}$ 7.2, and $200 \mu \mathrm{g} / \mathrm{ml}$ Amphotericin B (Sigma, St. Louis, MO). For iontophoretic application of ACh, sharp microelectrodes (resistance, 100-200 M $\Omega$ ) filled with $3 \mathrm{M}$ ACh chloride (Sigma) were used (Poo, 1982). Braking currents of 4-5 nA were used to prevent ACh leakage from the pipette, and constant iontophoretic current pulses of 10-20 nA amplitude and $1 \mathrm{msec}$ duration were delivered through a microelectrode amplifier (WPI) to the ACh pipette. The tip of the ACh pipette was bent slightly to facilitate the visualization of the tip and positioned tangentially into contact with the surface of the myocyte (see Fig. 4). Membrane currents were filtered at $10 \mathrm{kHz}$ and stored by a videotape recorder for later playback onto a storage oscilloscope (2201, Tektronix) or an oscillographic recorder (RS3200, Gould) and for analysis by a computer. The frequency, amplitude, and time course of synaptic currents were analyzed by using the SCAN program, kindly provided by Dr. J. Dempster (University of Strathclyde, Glasgow, Scotland).

\section{RESULTS}

The expression of NT-4 was elevated in a subpopulation of Xenopus myotomal myocytes by injection of NT-4 mRNA into one of the blastomeres of two-cell stage Xenopus embryos. The synaptic actions of NT-4 were examined by whole-cell patch- 


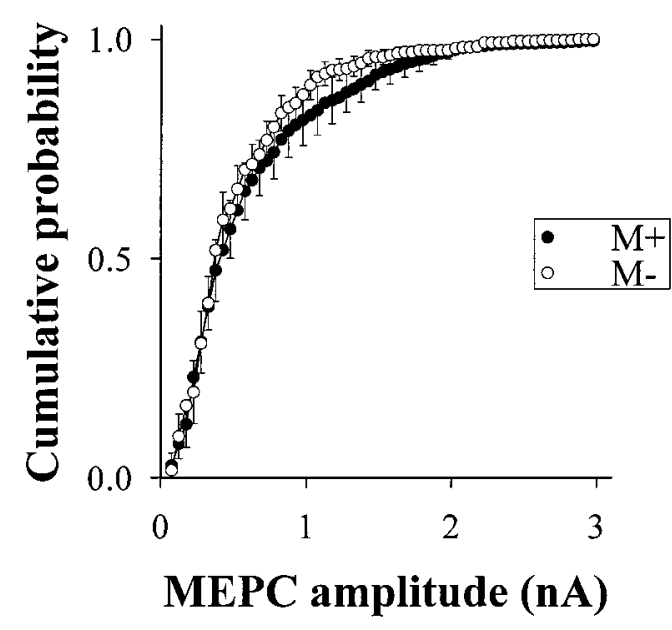

Figure 2. Comparison of MEPSC amplitude distribution recorded from pairs of $\mathrm{M}+$ ( filled circles) and $\mathrm{M}-$ (open circles) synapses innervated by the same neuron. The cumulative probability refers to the fraction of total events with amplitudes smaller than a given amplitude. Data points represent mean \pm SEM $(n=17$ triplets $)$. There was no significant difference between the two distributions ( $p>0.05$, Kolmogorov-Smirnov test).

clamp recording in nerve-muscle cultures prepared from embryos $1 \mathrm{~d}$ after injection. By co-injecting mRNA for GFP together with NT-4 message, NT-4-overexpressing cells were identified by the appearance of green fluorescence. As described previously, in these Xenopus nerve-muscle cultures synapses made on NT-4overexpressing myocytes $(\mathrm{M}+$ synapses) exhibited a higher level of spontaneous ACh secretion, more stable evoked ACh secretion, and an enhanced postsynaptic response to ACh compared with those made on control myocytes not expressing exogenous NT-4 mRNA (M- synapses) (Wang and Poo, 1997). These effects were attributable to NT-4 secretion from postsynaptic myocytes, because they were completely abolished by adding TrkB-IgG, a recombinant scavenger protein that binds to secreted NT-4, to the culture medium (Wang and Poo, 1997).

\section{Localized presynaptic action of NT-4}

In the present study, we first addressed the question of the spatial range of presynaptic action of NT-4 by using cultures that contained "triplet" circuits, which were single neurons innervating a pair of spherical myocytes of which only one was overexpressing NT-4 (Fig. 1A). We examined whether presynaptic modulation at $\mathrm{M}+$ synapses can spread to $\mathrm{M}-$ synapses within the triplet. Using whole-cell recording of synaptic currents from such paired synapses $(n=17)$, we found that the frequency of miniature EPSCs (MEPSCs) was in general higher at $\mathrm{M}+$ synapses than at $\mathrm{M}-$ synapses (see Figs. $1 B, 3 A$ ). However, the mean MEPSC amplitude at $\mathrm{M}+$ synapses $(558 \pm 79 \mathrm{pA})$ was not statistically different $(p>0.3, t$ test) from that at $\mathrm{M}-$ synapses $(475 \pm 53 \mathrm{pA})$. The distributions of MEPSC amplitudes were also not significantly different between $\mathrm{M}+$ and $\mathrm{M}-$ synapses (Fig. 2). In nine triplets from which successful paired recordings of evoked EPSCs from both synapses were obtained, the mean \pm SEM amplitude at $\mathrm{M}+$ synapses $(1.14 \pm 0.23 \mathrm{nA})$ was higher than that at $\mathrm{M}-$ synapses $(0.66 \pm 0.20 \mathrm{nA})$, although the difference was not statistically significant ( $p=0.15, t$ test). However, the coefficient of variation (CV) of the EPSC amplitude was significantly reduced at M+ synapses compared with that at $\mathrm{M}-$ synapses (Fig. $3 B$ ). $\mathrm{CV}$ is defined as the ratio of the SD to the mean value of the peak EPSC amplitude, and a reduction in $\mathrm{CV}$ indicates a reduced fluctuation of evoked responses. Overall, the effects on spontaneous and evoked synaptic currents at $\mathrm{M}+$ synapses are consistent with a presynaptic enhancement of transmitter secretion resulting from postsynaptic secretion of NT-4 (Wang and Poo, 1997). Furthermore, we found that the mean values of MEPSC frequency and the CV of EPSCs at $\mathrm{M}-$ synapses in these triplets were not significantly different from those found at singly innervated myocytes not expressing any exogenous message or expressing GFP message only (Fig. 3). Thus, M+ synapses had no apparent influence on $\mathrm{M}$ - synapses formed by the same neuron. The consistent differences in the synaptic properties observed between $\mathrm{M}+$ and $\mathrm{M}-$ synapses in the same culture, regardless of whether they were made by the same neuron, clearly indicated that the concentration of secreted NT-4 in the culture medium was ineffective in modifying the synapse.

To define the spatial range quantitatively, we studied the relationship of the distance between $\mathrm{M}+$ and $\mathrm{M}-$ synapses and several synaptic parameters at $\mathrm{M}-$ synapses. In these experiments, the direct extracellular "center-to-center" distance between NT-4-overexpressing myocytes and control myocytes innervated by the same neuron ranged from 50 to $230 \mu \mathrm{m}$, whereas the presynaptic cytoplasmic distance between the two synapses ranged from 60 to $360 \mu \mathrm{m}$. We reasoned that if the neurotrophin action may spread over a distance $>50 \mu \mathrm{m}$, then we should observe a neurotrophin effect on $\mathbf{M}$ - synapses in a distancedependent manner. When values for various synaptic parameters at $\mathrm{M}$ - synapses were plotted according to their extracellular or presynaptic cytoplasmic distances to the paired $\mathrm{M}+$ synapses, no apparent distance dependence was observed (Fig. 3). This suggests that NT-4 secreted from the NT-4-overexpressing myocyte was ineffective in modulating synapses on a nearby myocyte as close as $50 \mu \mathrm{m}$ away and that cytoplasmic changes leading to potentiated transmitter secretion in the presynaptic neuron were also spatially restricted within a distance of $\sim 60 \mu \mathrm{m}$. However, these results only provide an upper limit for the spatial range of retrograde neurotrophin action, because it is possible that secreted NT-4 may indeed affect synapses at distances smaller than those studied here. It is known that NT-4 secreted from an NT-4-overexpressing myocyte also causes an increase in the decay time of MEPSCs and EPSCs (Wang and Poo, 1997). An increase in the decay time of synaptic currents can be attributed to an increase in the mean bursting duration of $\mathrm{ACh}$ channels caused by autocrine regulation of ACh channels by NT-4 (Wang and Poo, 1997). In these triplet studies, we found that the halfdecay time of MEPSCs was significantly increased at M+ synapses but not at $\mathrm{M}$ - synapses formed by the same neuron (Fig. $3 C$ ). This result further supports the conclusion that the effective range of NT-4 secreted from a myocyte is restricted to $50 \mu \mathrm{m}$.

\section{Localized postsynaptic action of NT-4}

To further examine the postsynaptic action of NT-4, we performed a series of experiments in which the timing and the site of NT-4 secretion were more precisely defined. Localized NT-4 secretion was triggered by repetitive iontophoretic application of ACh pulses at a high frequency to the surface of isolated NT-4overexpressing myocytes while the myocyte was whole-cell voltage-clamped at its resting potential. The secretion of NT-4 was monitored indirectly as an increase in the decay time of ACh-induced currents elicited by low-frequency test ACh pulses at the site of tetanic ACh stimulation. As shown in Figure 4, within minutes after a train of tetanic $\mathrm{ACh}$ pulses $(4 \mathrm{~Hz}, 1 \mathrm{~min})$, 
Figure 3. Summary of paired recordings of synaptic currents at $\mathrm{M}+$ (closed circles) and $\mathrm{M}-$ (open circles) synapses made by the same neuron. A, left, MEPSC frequencies at $\mathrm{M}+$ and $\mathrm{M}-$ synapses observed at 17 triplets; data from the same triplet are connected by a line. Middle, All data in the left graph for $\mathrm{M}$ - synapses are plotted against the center-to-center distance between the two myocytes of each triplet (open circles) and against the presynaptic cytoplasmic distance between the $\mathrm{M}+$ and M- synapses (open triangles). Dashed and solid lines represent the best linear fit of the data for center-to-center and cytoplasmic distances, respectively. Right, NT-4 + GFP, The mean values of MEPSC frequency at M+ and M- synapses of 17 triplets obtained from cultures made from embryos injected with both NT-4 and GFP messages; GFP, data from cultures made from embryos injected with GFP mRNA only $(n=16$ for M- synapses; $n=13$ for M+ synapses). Bars represent mean \pm SEM. Asterisk marks data that were significantly different from corresponding control values $(\mathrm{M}+$ vs $\mathrm{M}-$ values; $p<$ 0.05 , paired $t$ test). $B$, CV of EPSCs recorded from $\mathrm{M}+$ and $\mathrm{M}-$ myocytes in nine triplets. CV of EPSCs was calculated as the ratio of the SD to the mean value of the peak EPSC amplitude. $C$, Half-decay times of MEPSCs recorded from paired $\mathrm{M}+$ and $\mathrm{M}-$ myocytes in 17 triplets. Graphs in $B$ and $C$ are plotted in the same manner as that described in $A$.

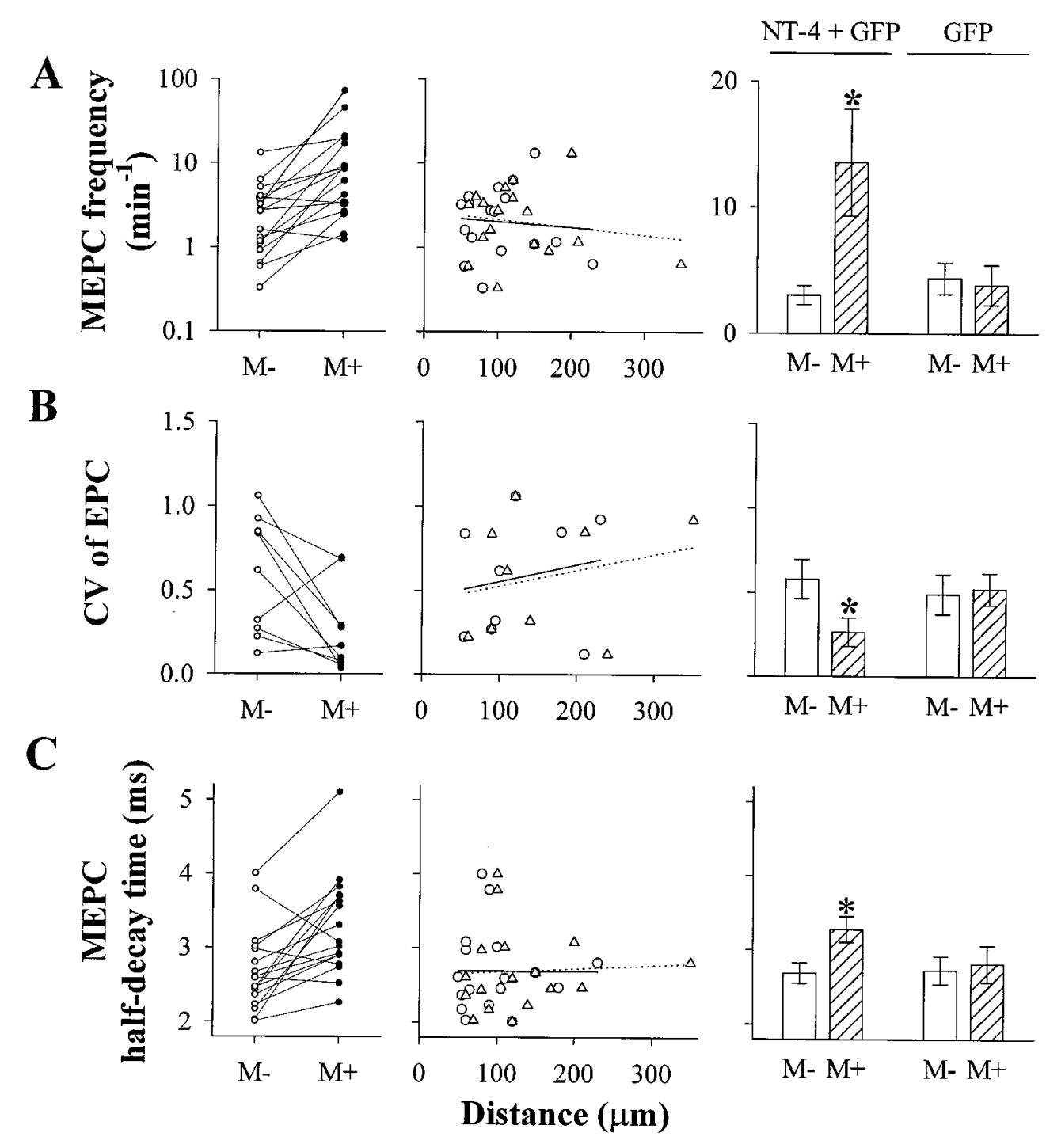

the half-decay time of ACh currents induced by test ACh pulses $(0.05 \mathrm{~Hz})$ was significantly prolonged in NT-4-overexpressing myocytes $(\mathrm{M}+)$ but not in control myocytes $(\mathrm{M}-)$. No significant change was found for the rise time and amplitude of ACh currents after tetanic ACh stimulation (Fig. 4). The time course and magnitude of ACh-induced membrane currents were qualitatively similar to synaptic currents observed at developing synapses, and the effect of tetanic ACh stimulation on the decay time of ACh-induced currents was similar to that found for synaptic currents after repetitive presynaptic stimulation (Wang and Poo, 1997). The effect of tetanic ACh stimulation on the decay time of ACh-induced currents can be attributed to the stimulationinduced secretion of NT-4 from the myocyte, because in the presence of TrkB-IgG $(1 \mu \mathrm{g} / \mathrm{ml})$, no change in the decay time was observed (Fig. 5). The blocking effect of TrkB-IgG on the NT-4 action on the decay time was specific because TrkA-IgG was not effective (Wang and Poo, 1997). Furthermore, bath application of K252a (200 nM), an inhibitor of the tyrosine kinase of Trk receptors, abolished the effect (Fig. 5). This indicates that TrkB signaling is required for the NT-4 action on the ACh channel. Finally, the effect was not observed in myocytes expressing GFP message only (Fig. 5). Thus, iontophoretic ACh application is an effective means in triggering NT-4 secretion and in providing a physiological assay of the action of secreted NT-4.

To further delineate the range of postsynaptic action of secreted NT-4, we examined the spatial distribution of NT-4induced modulation of ACh channels in the myocyte membrane. Specifically, we measured the effect of tetanic ACh pulses $(4 \mathrm{~Hz}$, $1 \mathrm{~min})$ on the decay time of ACh-induced currents at different distances from the site of tetanic ACh stimulation. Two types of myocytes were used. For spherical myocytes of different diameters, ACh-induced currents were measured by applying test ACh pulses at the site of tetanic ACh application (stimulation site) and at the pole opposite to the stimulation site (control site) (Fig. 6A). Considering all myocytes that we have examined (range of diameter, 31-43 $\mu \mathrm{m}$ ), the effect of tetanic ACh stimulation on the decay time of ACh currents appeared with a slower time course at the control site (Fig. 6B). Plotting the data according to the myocyte diameter revealed a dependence of the effect on the size of the myocyte (Fig. 6C). During the 5-20 min after the tetanic stimulation, the decay time was similarly prolonged at both the stimulation and control sites in myocytes with a diameter between 31 and $34 \mu \mathrm{m}$. The effect on the control site was significantly reduced for myocytes with a diameter between 34 and $37 \mu \mathrm{m}$ and 


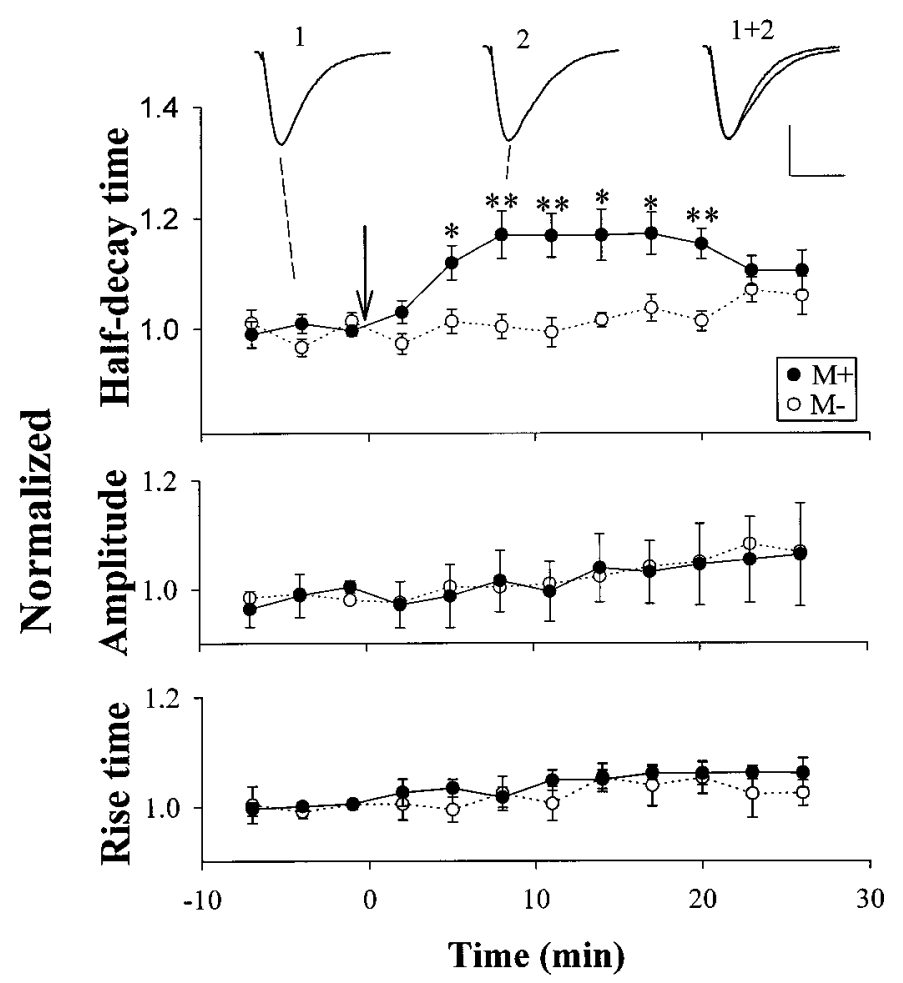

Figure 4. Modulation of ACh-induced currents in myocytes by activityinduced secretion of NT-4. Half-decay time, peak amplitude, and rise time of ACh-induced currents at various times before and after tetanic ACh stimulation. Tetanic ACh pulses $(4 \mathrm{~Hz}, 1 \mathrm{~min})$ were applied iontophoretically at time 0 to the myocyte surface (arrow). Sample traces (average of 12 events) for ACh-induced currents before (1) and after (2) tetanic ACh stimulation are shown above. Calibration: $0.25 \mathrm{nA}, 5$ msec. All data are normalized to the mean value during the control period before the tetanic stimulation (mean $\pm \mathrm{SEM} ; n=9$ for $\mathrm{M}+; n=7$ for $\mathrm{M}-$ ). Asterisks mark data that were significantly different from corresponding control values ( $\mathrm{M}+\mathrm{vs} \mathrm{M}-$ values; ${ }^{*} p<0.05$; ${ }^{*} p<0.01, t$ test $)$.

completely disappeared for myocytes with a diameter of $>37 \mu \mathrm{m}$. Thus, both the secretion of NT-4 induced by tetanic ACh pulses and the action of NT-4 on myocyte ACh channels did not spread beyond a distance of $\sim 40 \mu \mathrm{m}$ in the cytoplasm or $\sim 60 \mu \mathrm{m}$ in the extracellular space, respectively. In the second set of experiments using spindle-shaped myocytes, ACh-induced currents were measured at four different distances $(0,25,50$, and $75 \mu \mathrm{m})$ from the site of tetanic ACh stimulation (Fig. $7 A$ ). The effect of tetanic ACh pulses in prolonging the decay time was clearly observed at 0,25 , and $50 \mu \mathrm{m}$ but not at $75 \mu \mathrm{m}$ (Fig. $7 B$ ). Together with the result obtained from spherical myocytes, we conclude that after tetanic ACh stimulation, the site of NT-4 secretion, the diffusion of NT-4 in the extracellular space, and the cytoplasmic spread of NT-4-activated downstream signaling events responsible for ACh channel modulation are all restricted within a range of $\sim 60 \mu \mathrm{m}$.

\section{DISCUSSION}

Previous work has shown that local application of exogenous neurotrophins can induce localized changes in the morphology of nerve growth cones and in the secretion of neurotransmitters from presynaptic nerve terminals (Campenot, 1977; Seeley and Greene, 1983; Stoop and Poo, 1995). However, it is unknown over which distance neurotrophins secreted locally from a cell can exert their influence on the structure and function of the synapse. Using Xenopus nerve-muscle cultures, we have quantitatively

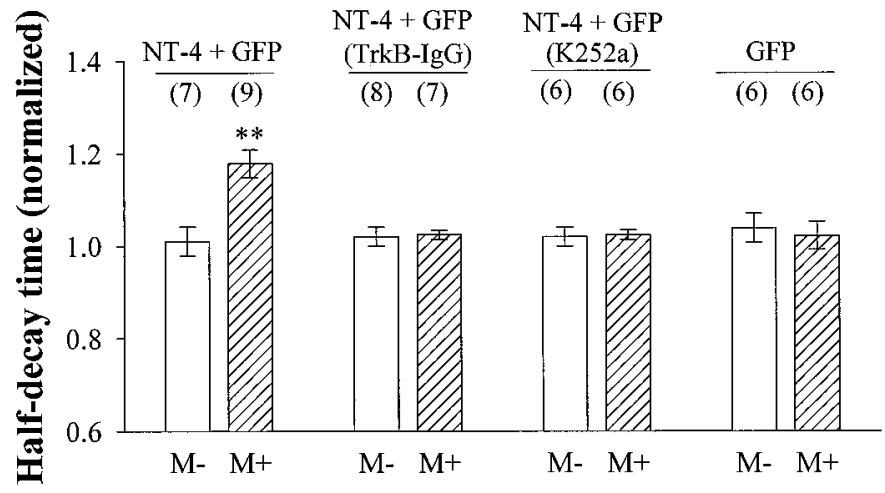

Figure 5. Half-decay time of ACh-induced currents during 5-20 min after tetanic ACh application at NT-4-overexpressing $(M+)$ and control $(M-)$ myocytes. Data (mean \pm SEM) are normalized to the mean value during the control period for each myocyte. The number associated with each bar refers to the total number of myocytes examined. NT-4 $+G F P$, Cultures prepared from embryos injected with NT-4 and GFP mRNAs; $N T-4+G F P(\operatorname{TrkB}-\operatorname{Ig} G)$, the same as the group of NT-4 + GFP, except that TrkB-IgG $(1 \mu \mathrm{g} / \mathrm{ml})$ was applied to the culture medium during recording; NT-4 + GFP $(K 252 a)$, the same as the group of NT-4 + GFP, except that K252a (200 $\mathrm{nM}$ ) was applied to the culture medium during recording; GFP, cultures prepared from embryos injected with GFP mRNA alone. **Data significantly different from their corresponding control values $(\mathrm{M}+\mathrm{vs} \mathrm{M}-$ values; $p<0.01, t$ test $)$.

assayed the spatial range of presynaptic and postsynaptic actions of secreted NT-4. For the presynaptic action on the transmitter release mechanisms, our data provided an upper limit of 50-60 $\mu \mathrm{m}$ for the spread of NT-4 action within the presynaptic neuron. For the postsynaptic NT-4 action on ACh channel kinetics, which we were able to monitor with higher spatial resolution, we found that the NT-4 effect can spread up to $50 \mu \mathrm{m}$ but not $>60 \mu \mathrm{m}$ from the site at which NT-4 secretion was induced in the myocyte. This result suggests that both the diff usion of secreted NT-4 molecules in the extracellular space and the spread of downstream effectors of NT-4 signaling in the cytoplasm are restricted to $\sim 50 \mu \mathrm{m}$.

Using an embryo injection technique, NT-4 levels were transiently elevated in approximately half of the cells in these Xenopus nerve-muscle cultures. The levels of NT-4 overexpression and of NT-4 basal secretion achieved in the present study were nonsaturating, indicating that they were likely within a physiological range. As shown previously, NT-4 release evoked by highfrequency synaptic stimulation in this preparation was effective in further potentiating the presynaptic transmitter release, as well as in modulating postsynaptic ACh receptor properties (Wang and Poo, 1997).

Electrical or synaptic activity has been shown to regulate the synthesis of BDNF and NGF in hippocampal cultures (Zafra et al., 1990; Lu et al., 1991), of NT-4 in rat skeletal muscle (Funakoshi et al., 1995), and of NT-3 in cultured Xenopus myocytes (Xie et al., 1997). Our present and previous (Wang and Poo, 1997) findings indicate that synaptic activity can regulate the secretion of NT-4 from Xenopus myocytes, consistent with previous results on depolarization-induced NGF and BDNF secretion (Blöchl and Thoenen, 1995; Goodman et al., 1996). Whereas activity-dependent neurotrophin synthesis regulates the amount of available neurotrophin with relatively slow kinetics, neurotrophin secretion induced by synaptic activity provides a means for controlling the availability of neurotrophins at a synapse on a much more rapid time scale, thereby temporally coupling presynaptic activity to postsynaptic neurotrophin secretion. An increase 
A

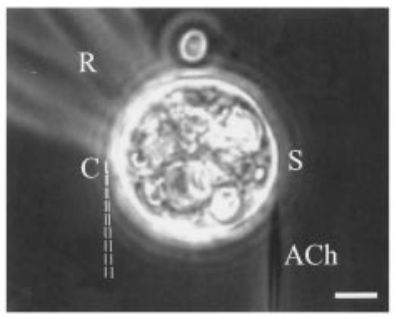

B

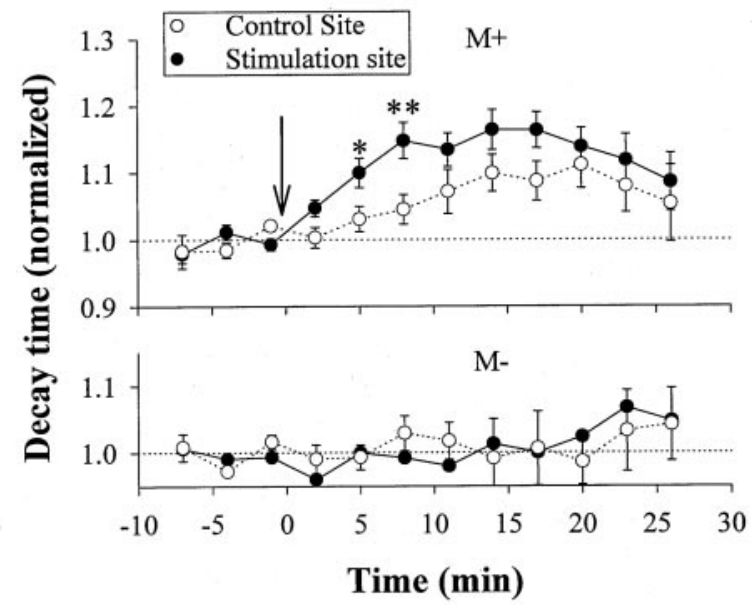

C

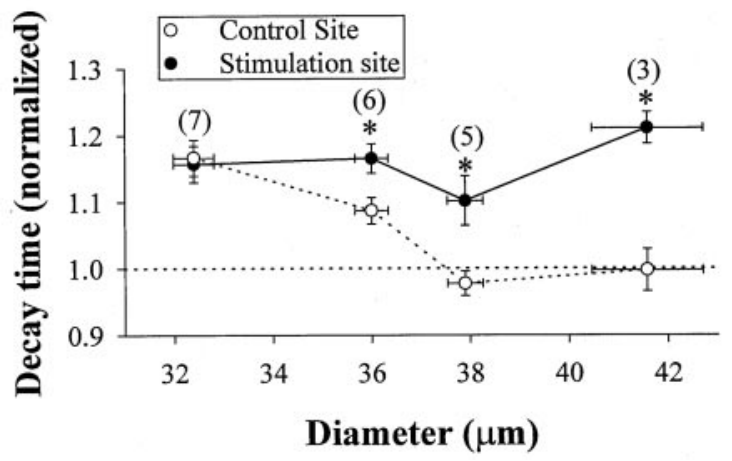

Figure 6. Localized modulation of ACh-induced currents by secreted NT-4 at spherical myocytes. $A$, Phase-contrast image of a spherical Xenopus myocyte in 1-d-old culture. The membrane current of the myocyte was monitored by a whole-cell recording pipette $(R)$. The same iontophoresis pipette $(A C h)$ was used for tetanic ACh stimulation at stimulation sites $(S)$, as well as for delivering ACh pulses at a low frequency as test pulses at both $S$ and control sites $(C)$. B , Half-decay time of ACh-induced currents at control and stimulation sites after tetanic ACh stimulation of NT-4overexpressing $(M+)$ and control $(M-)$ myocytes. Tetanic ACh pulses $(4$ $\mathrm{Hz}, 1 \mathrm{~min}$ ) were applied at time 0 . All data are normalized to the mean value obtained during the control period before tetanic stimulation (mean $\pm \mathrm{SEM} ; n=21$ for $\mathrm{M}+; n=9$ for $\mathrm{M}-$ ). Asterisks mark data significantly different from values at control sites measured in the same period $\left({ }^{*} p<0.05 ;{ }^{*} p<0.01, t\right.$ test $)$. $C$, Dependence of the decay time on the myocyte diameter. Normalized half-decay times of ACh-induced currents at 5-20 min after tetanic ACh stimulation at control and stimulation sites were averaged for groups of myocytes with diameters between 31 and $43 \mu \mathrm{m}$ in $3 \mu \mathrm{m}$ bins. Asterisks mark data significantly different from values at control sites measured in the same period ( $p<0.05, t$ test).

in the rate of neurotrophin synthesis may also contribute to replenishing the pool of releasable neurotrophins upon secretion. Because neurotrophins have been shown to potentiate synaptic transmission, regulation of both synthesis and secretion by activity results in a positive feedback at active synapses, and such
A

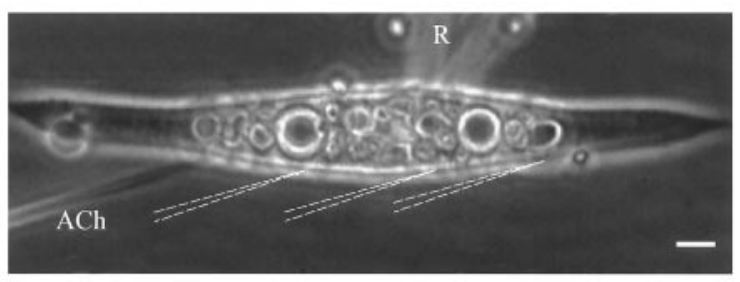

\section{B}

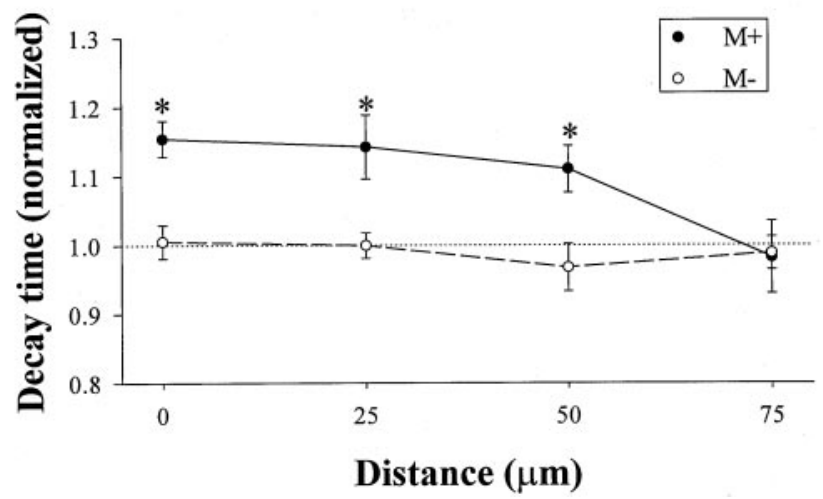

Figure 7. Localized modulation of ACh-induced currents by secreted NT-4 at spindle myocytes. $A$, Phase-contrast image of a Xenopus spindle myocyte. Tetanic ACh pulses $(4 \mathrm{~Hz}, 1 \mathrm{~min}$ ) were applied to one site by an ACh iontophoresis pipette $(A C h)$, and ACh-induced test currents were monitored at $0,25,50$, and $75 \mu \mathrm{m}$ from the site of tetanic ACh stimulation. $B$, Dependence of the decay time on the distance from the site of tetanic stimulation. Normalized decay times 5-20 min after tetanic ACh stimulation were averaged for seven NT-4-overexpressing $(M+)$ and six control $(M-)$ spindle myocytes. Asterisks mark data significantly different from values obtained from $\mathrm{M}-$ myocytes $(p<0.05, t$ test $)$.

mechanisms may be used to strengthen or stabilize these synaptic connections.

Overexpressing myocytes also appeared to secrete NT-4 constitutively. This is suggested by the findings that an increase in the mean burst duration of ACh receptors was observed in singlechannel recordings from isolated NT-4-overexpressing myocytes compared with that found in control myocytes, and that this effect was blocked by the presence of TrkB-IgG (Wang and Poo, 1997). Constitutive secretion of NT-4 may also account for the elevated frequency of spontaneous transmitter release and the reduced fluctuation of evoked transmitter release, although it remains unclear to what extent the synaptic activity attributable to spontaneous secretion of ACh also plays a significant part in triggering NT-4 secretion from the myocyte. Secretion triggered by spontaneous synaptic activity may also be considered constitutive because it is independent of the action potential in the presynaptic neuron. During development of the nervous system, constitutive neurotrophin secretion may serve to maintain basal synaptic function, whereas action potential-triggered neurotrophin secretion may be responsible for activity-dependent modulation of synaptic connections.

It has been proposed that during the process of synapse refinement by activity, nerve terminals compete for limiting amounts of neurotrophic factors secreted by the target cell (Purves and Lichtman, 1985). There is evidence that neurotrophins are required for the formation of ocular dominance columns (Maffei et al., 
1992; Cabelli et al., 1995, 1997). The highly localized action of neurotrophin may provide a mechanism for retaining specificity of synaptic modification during the process of synapse refinement. Thus, activity-dependent synthesis, activity-triggered local secretion, and localized synaptic action of neurotrophins may all contribute to the selective stabilization of active synaptic connections. In sharp contrast to the localized presynaptic action of NT-4, activity-induced long-term depression in these Xenopus neuromuscular synapses can spread presynaptically over a distance of $400 \mu \mathrm{m}$ to neighboring synapses formed by the same axon on other myocytes (Cash et al., 1996). The coexistence of such opposite signaling mechanisms involved in synaptic modulation may help ensure effective pruning of developing synapses during the process of synapse elimination.

Previous studies have shown that presynaptic potentiation of transmitter secretion at $\mathrm{M}+$ synapses represents a long-lasting synaptic modification that cannot be reversed by a $1 \mathrm{hr}$ incubation of TrkB-IgG (Wang and Poo, 1997). Thus, long-term synaptic actions of neurotrophins can be localized. Such a localized effect indicates that the activated intracellular effector molecules associated with the TrkB signaling pathway must be spatially restricted within a range $<60 \mu \mathrm{m}$ from the site of synaptic contact with the NT-4-overexpressing myocyte. On the other hand, target-derived trophic factors are known to affect neuronal survival and maintenance of global neuronal properties of the presynaptic neuron (Barde, 1989; Oppenheim, 1991; Lewin and Barde, 1996), including the efficacy of synaptic inputs on its dendrites (Purves and Nja, 1978). The present results thus underscore the existence of two distinct modes of the action of neurotrophins as retrograde factors: a local action involving spatially restricted activation of Trk transduction pathways and their downstream substrates, and a global somatic action that depends on axonal transport of either internalized neurotrophin-receptor complexes or downstream effector molecules in the Trk transduction pathway.

Using a cultured Aplysia sensory neuron with bifurcating neurites synapsing on two separated motoneurons, Martin et al. (1997) have recently demonstrated a branch-specific long-term facilitation. When synapses formed by one branch of the sensory neuron axon were locally perfused with serotonin, long-term facilitation was restricted to the site of perfusion and did not spread to the synapses formed by the unperfused branch, an effect that required local protein synthesis and involved the growth of new synapses on the perfused branch. Interestingly, long-term facilitation at Aplysia sensory-motoneuron synapses seems to require endogenous TGF $\beta$ and is occluded by treatment with exogenous TGF $\beta$ (Zhang et al., 1997). It is possible that TGF $\beta$ and NT-4 exert their highly localized action on the presynaptic neuron via similar cellular mechanisms.

LTP induced by activation of specific synaptic inputs to CA1 pyramidal neurons in hippocampal slice cultures is accompanied by a spread of synaptic potentiation to adjacent synapses made by other presynaptic inputs to the same postsynaptic neuron (Engert and Bonhoeffer, 1997). The distance of affected synapses was found to be $<70 \mu \mathrm{m}$. Such restricted spread of LTP could be attributed to the localized action of secreted factors similar to that shown here. It is known that gene expression and protein synthesis are required for the maintenance of long-term synaptic modification (Nguyen et al., 1994; Kang and Schuman, 1996; Martin et al., 1997). Therefore, some local signal(s) must persist to preserve synapse specificity. One intriguing possibility is that a synaptic "tag" (Frey and Morris, 1997; Martin et al., 1997) is established by the initial action of locally secreted neurotrophins and that global gene activation results in long-term potentiation specifically of those synapses carrying the tag.

\section{REFERENCES}

Barde Y-A (1989) Trophic factors and neuronal survival. Neuron 2:1525-1534.

Berninger B, Poo MM (1996) Fast actions of neurotrophic factors. Curr Opin Neurobiol 6:324-330.

Blöchl A, Thoenen H (1995) Characterization of nerve growth factor (NGF) release from hippocampal neurons: evidence for a constitutive and an unconventional sodium-dependent regulated pathway. Eur J Neurosci 7:1220-1228.

Bonhoeffer T (1996) Neurotrophins and activity-dependent development of the neocortex. Curr Opin Neurobiol 6:119-126.

Bonhoeffer T, Staiger V, Aertsen A (1989) Synaptic plasticity in rat hippocampal slice cultures: local "Hebbian" conjunction of pre- and postsynaptic stimulation leads to distributed synaptic enhancement. Proc Natl Acad Sci USA 86:8113-8117.

Cabelli RJ, Hohn A, Shatz CJ (1995) Inhibition of ocular dominance column formation by infusion of NT-4/5 or BDNF. Science 267:1662-1666.

Cabelli RJ, Shelton DL, Segal RA, Shatz CJ (1997) Blockade of endogenous ligands of trkB inhibits formation of ocular dominance columns. Neuron 19:63-76.

Campenot RB (1977) Local control of neurite development by nerve growth factor. Proc Natl Acad Sci USA 74:4516-4519.

Cash S, Zucker RS, Poo MM (1996) Spread of synaptic depression mediated by presynaptic cytoplasmic signaling. Science 272:998-1001.

Cellerino A, Maffei L (1996) The action of neurotrophins in the development and plasticity of the visual cortex. Prog Neurobiol 49:53-71.

Engert F, Bonhoeffer T (1997) Synapse specificity of long-term potentiation breaks down at short distances. Nature 388:279-284.

Evers J, Laser M, Sun YA, Xie ZP, Poo MM (1989) Studies of nervemuscle interactions in Xenopus cell culture: analysis of early synaptic currents. J Neurosci 9:1523-1539.

Figurov A, Pozzo-Miller LD, Olafsson P, Wang T, Lu B (1996) Regulation of synaptic responses to high-frequency stimulation and LTP by neurotrophins in the hippocampus. Nature 381:706-709.

Fitzsimonds RM, Song HJ, Poo MM (1997) Propagation of activitydependent synaptic depression in simple neural networks. Nature 388:439-448.

Frey U, Morris RG (1997) Synaptic tagging and long-term potentiation. Nature 385:533-536.

Funakoshi H, Belluardo N, Arenas E, Yamamoto Y, Casabona A, Persson H, Ibáñez CF (1995) Muscle-derived neurotrophin-4 as an activity-dependent trophic signal for adult motor neurons. Science 268:1495-1499.

Gall CM, Isackson PJ (1989) Limbic seizures increase neuronal production of messenger RNA for nerve growth factor. Science 245:758-761.

Goodman LJ, Valverde J, Lim F, Geschwind MD, Federoff HJ, Geller AI, Hefti F (1996) Regulated release and polarized localization of brain-derived neurotrophic factor in hippocampal neurons. Mol Cell Neurosci 7:222-238.

Hamill OP, Marty A, Neher E, Sakmann B, Sigworth FJ (1981) Improved patch-clamp techniques for high-resolution current recording from cells and cell-free membrane patches. Pflügers Arch 391:85-100.

Kang H, Schuman EM (1995) Long-lasting neurotrophin-induced enhancement of synaptic transmission in the adult hippocampus. Science 267:1658-1662.

Kang H, Schuman EM (1996) A requirement for local protein synthesis in neurotrophin-induced hippocampal synaptic plasticity. Science 273:1402-1406.

Kang H, Welcher AA, Shelton D, Schuman EM (1997) Neurotrophins and time: different roles for TrkB signaling in hippocampal long-term potentiation. Neuron 19:653-664.

Katz LC, Shatz CJ (1996) Synaptic activity and the construction of cortical circuits. Science 274:1133-1138.

Kim HG, Wang T, Olafsson P, Lu B (1994) Neurotrophin 3 potentiates neuronal activity and inhibits gamma-aminobutyratergic synaptic transmission in cortical neurons. Proc Natl Acad Sci USA 91:12341-12345.

Korte M, Carroll P, Wolf E, Brem G, Thoenen H, Bonhoeffer T (1995) Hippocampal long-term potentiation is impaired in mice lacking brainderived neurotrophic factor. Proc Natl Acad Sci USA 92:8856-8860. 
Korte M, Griesbeck O, Gravel C, Carroll P, Staiger V, Thoenen H, Bonhoeffer T (1996) Virus-mediated gene transfer into hippocampal CA1 region restores long-term potentiation in brain-derived neurotrophic factor mutant mice. Proc Natl Acad Sci USA 93:12547-12552.

Lessmann V, Gottmann K, Heumann R (1994) BDNF and NT-4/5 enhance glutamatergic synaptic transmission in cultured hippocampal neurons. NeuroReport 6:21-25.

Levine ES, Dreyfus CF, Black IB, Plummer MR (1995) Brain-derived neurotrophic factor rapidly enhances synaptic transmission in hippocampal neurons via postsynaptic tyrosine kinase receptors. Proc Natl Acad Sci USA 92:8074-8077.

Lewin GR, Barde Y-A (1996) Physiology of the neurotrophins. Annu Rev Neurosci 19:289-317.

Lo DC (1995) Neurotrophic factors and synaptic plasticity. Neuron 15:979-981.

Lohof AM, Ip NY, Poo MM (1993) Potentiation of developing neuromuscular synapses by the neurotrophins NT-3 and BDNF. Nature 363:350-353.

Lu B, Yokoyama M, Dreyfus CF, Black IB (1991) Depolarizing stimuli regulate nerve growth factor gene expression in cultured hippocampal neurons. Proc Natl Acad Sci USA 88:6289-6292.

Maffei L, Berardi N, Domenici L, Parisi V, Pizzorusso T (1992) Nerve growth factor (NGF) prevents the shift in ocular dominance distribution of visual cortical neurons in monocularly deprived rats. J Neurosci 12:4651-4662.

Martin KC, Casadio A, Zhu H, E Y, Rose JC, Chen M, Bailey CH, Kandel ER (1997) Synapse-specific, long-term facilitation of Aplysia sensory to motor synapses: a function for local protein synthesis in memory storage. Cell 91:927-938.

Nguyen PV, Abel T, Kandel ER (1994) Requirement of a critical period of transcription for induction of a late phase of LTP. Science 265:1104-1107.

Oppenheim RW (1991) Cell death during development of the nervous system. Annu Rev Neurosci 14:453-501.

Patterson SL, Abel T, Deuel TA, Martin KC, Rose JC, Kandel ER (1996) Recombinant BDNF rescues deficits in basal synaptic transmission and hippocampal LTP in BDNF knockout mice. Neuron 16:1137-1145.

Poo MM (1982) Rapid lateral diffusion of functional ACh receptors in embryonic muscle cell membrane. Nature 295:332-334.
Purves D, Lichtman JW (1985) Principles of neural development. Sunderland, MA: Sinauer.

Purves D, Nja A (1978) Neuronal plasticity (Cotman CW, ed), pp 27-47. New York: Raven.

Schuman EM (1997) Synapse specificity and long-term information storage. Neuron 18:339-342.

Schuman EM, Madison DV (1994) Locally distributed synaptic potentiation in the hippocampus. Science 263:532-536.

Seeley PJ, Greene LA (1983) Short-latency local actions of nerve growth factor at the growth cone. Proc Natl Acad Sci USA 80:2789-2793.

Spitzer NC, Lamborghini JE (1976) The development of the action potential mechanism of amphibian neurons isolated in culture. Proc Natl Acad Sci USA 73:1641-1645.

Stoop R, Poo MM (1995) Potentiation of transmitter release by ciliary neurotrophic factor requires somatic signaling. Science 267:695-699.

Tabti N, Poo MM (1991) Culturing spinal cord neurons and muscle cells from Xenopus embryos. In: Culturing nerve cells (Banker G, Goslin K, eds), pp 137-154. Cambridge, MA: MIT.

Thoenen H (1995) Neurotrophins and neuronal plasticity. Science 270:593-598.

Wang XH, Poo MM (1997) Potentiation of developing synapses by postsynaptic release of neurotrophin-4. Neuron 19:825-835.

Xie K, Wang T, Olafsson P, Mizuno K, Lu B (1997) Activity-dependent expression of NT-3 in muscle cells in culture: implications in the development of neuromuscular junctions. J Neurosci 17:2947-2958.

Zafra F, Hengerer B, Leibrock J, Thoenen H, Lindholm D (1990) Activity-dependent regulation of BDNF and NGF mRNAs in the rat hippocampus is mediated by nonNMDA glutamate receptors. EMBO J 9:3545-3550.

Zafra F, Castren E, Thoenen H, Lindholm D (1991) Interplay between glutamate and gamma-aminobutyric acid transmitter systems in the physiological regulation of brain-derived neurotrophic factor and nerve growth factor synthesis in hippocampal neurons. Proc Natl Acad Sci USA 88:10037-10041.

Zhang F, Endo S, Cleary LJ, Eskin A, Byrne JH (1997) Role of transforming growth factor- $\beta$ in long-term synaptic facilitation in Aplysia. Science 275:1318-1320. 